\title{
Resists Using the Absorption Band Shift Method for ArF Excimer Laser Lithography
}

\author{
Takeshi Okino, Koji Asakawa, Naomi shida and Tohru Ushirogouchi
}

\begin{abstract}
Materials and Devices Research Laboratories, Research and Development center Toshiba corporation, 1, Komukai Toshiba-cho, Saiwai-ku, Kawasaki 210-8582, Japan.
\end{abstract}

Keywords: ArF, absorption band shift, naphthalene, dissolution inhibitor

\section{Introduction}

The integration of LSI has been increasing year after year, and mass-producing $1 \mathrm{G}$ bit DRAM will start from the beginning of the next century. Resist patterns of less than $0.15 \mu \mathrm{m}$ lines/spaces must be required at the coming age. Optical lithography excels in the throughput of the semiconductor fabrication, thereby $\operatorname{ArF}(\lambda=193$ $\mathrm{nm}$ ) excimer laser lithography is thought to be the most powerful candidate of the lithographic technology for the post $\mathrm{KrF} \quad(\lambda=248 \mathrm{~nm})$ generation.

The previously-used resist materials comprising benzene rings such as Novolak resin, poly-hydroxy phenol resin and so on have poor transparency to ArF excimer laser light. We have proposed naphthalene ${ }^{1)}$ and alicyclic material such as menthol ${ }^{2)}$ to overcome this problem. Naphthalene is a material for which the absorption band shift method ") for ArF excimer laser lithography is used and it has excellent dry etch resistance. In this method, absorption is shifted to a greater wavelength by extending the conjugate length of the aromatic ring. On the other hand, menthol, which is a natural product, demonstrates good dry etch resistance and high transparency to $\mathrm{ArF}$ excimer laser light. Di-tert-butyl 2-((1-adamanthyl) carbonyl-methyl) malonate (ADTB) ${ }^{3)}$ has also been introduced as a dissolution inhibitor to control a fine desolution rate.

Additionally, recent progress of Chemical Mechanical Polishing (CMP) techniques has made possible the fabrication of finer patterns by using flattened and thin resist films.

\section{Experimental}

2.1. Materials

Mixtures of vinylnaphthalene, menthyl acrylate, tetrahydropyranyl methacrylate and methacrylic acid were polymerized in tetrahydrofuran using $2,2^{\prime}$-azobis(isobutyronitrile) as an initiator at $60^{\circ} \mathrm{C}$ for $\mathbf{4 0}$ hours to obtain base resins. The structure of the copolymer is shown in Fig.1.

ADTB was synthesized from di-tert-butyl malonate and 1-adamantyl bromomethyl ketone. The structure of ADTB is shown in Fig.2. The identification of ADTB was performed by NMR.

Triphenylsulfoniumtriflate (TPS-105, Midori Kagaku Co., Ltd.) was used as a photo-acid generator. The amount of the photo-acid generator to the resin, the base polymer and the dissolution inhibitor, was 1 wt\%. Propylene glycol monomethyl ether acetate was used as a solvent.

\subsection{Measurements}

UV spectra were measured with UV-3101PC (SHIMADZU Co.). Molecular weight of the polymers was measured using GPC chromatography CTO-10A (SHIMADZU Co.). Dry etch resistance of the resists was measured by DEM-451 (ANELVA Co., Ltd.) reactive ion etcher. The etch conditions were as follows: gas; $\mathbf{C F}_{4}$, pressure; 0.01 torr, flowing quantity; $30.0 \mathrm{sccm}$, and output power; $150 \mathrm{~W}$. 2.38\% TMAH aqueous 
solution (AD-10, Tama Chemicals Co. Ltd.) was diluted for use as a developer. The prototype ArF

excimer laser exposure equipment (Nikon Co., $\mathrm{NA}=0.55$ ) was used to expose resist films.

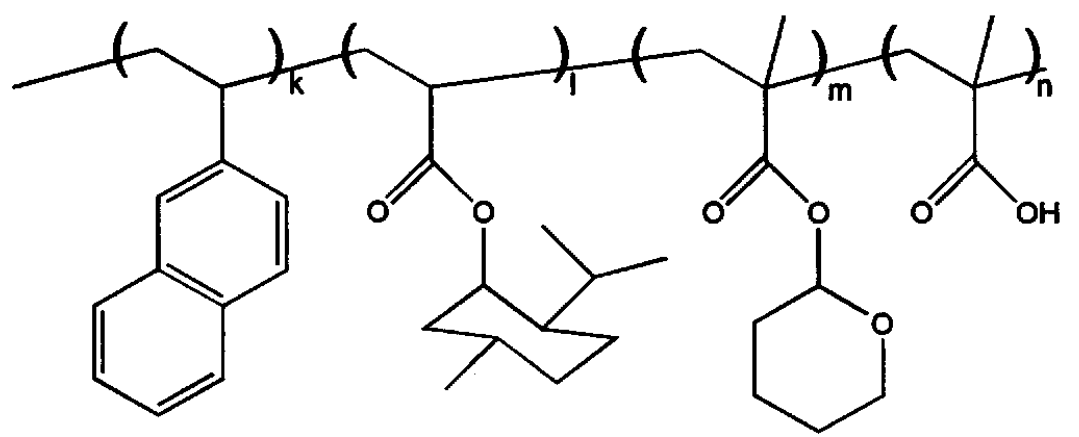

Fig. 1 Structure of copolymer using in this study

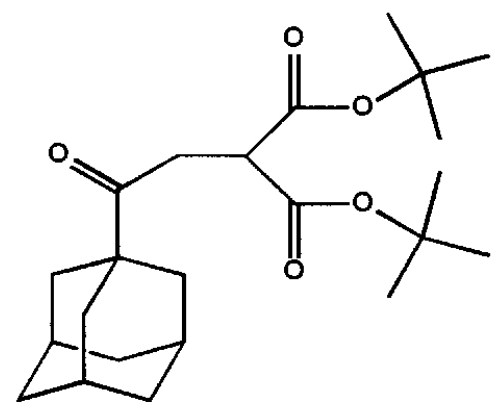

Fig.2 Structure of ADTB

\section{Results and Discussion}

Naphthalene has excellent dry etch resistance, and so we wanted to introduce as much of it as possible. The absorbance and transparency of copolymers (copolymerization ratio; vinylnaphthalene / menthyl acrylate / tetrahydropyranyl methacrylate / methacrylic acid $=x / 45-x / 33 / 22 \mathrm{~mol}$ ) were measured. The absorbance was increased by introducing vinylnaphthalene as shown in Fig.3. As mentioned above, naphthalene is a material for which the absorption band shift method for ArF excimer laser lithography is used. Its transparency at $193 \mathrm{~nm}$ is greatly superior to that of benzene, but is somewhat poorer than that of an alicyclic compound since a little absorption remains. About $50 \%$ or more transparency is required for fabrication of fine patterns. Judging from the absorbance in Fig.3, it would be impossible to introduce much vinylnaphthalene. Then, the limit of the introducing ratio was considered. The transparency also depends on the thickness of a resist film. The transparency was increased by thinning a film as shown in Fig.3. For example, the transparency of a $0.30 \mu \mathrm{m}$-thick VN25 (copolymerization ratio; vinylnaphthalene / menthyl acrylate / tetrahydropyranyl methacrylate / methacrylic acid $=25 / 20 / 33 / 22 \mathrm{~mol}$ ) resist film was $25 \%$ while that of a $0.15 \mu \mathrm{m}$-thick film of the same composition was $50 \%$. These results suggested that the thin VN25 resist film has transparency within limits, so we studied it. The weight average molecular weight of VN25 polymer was typically 8,400 .

The etch resistance tends to be higher in accordance with the introduction of ADTB. In the case that more than $25 \mathrm{wt} \%$ of ADTB was introduced, the VN25/ADTB resist had a higher etch resistance than a conventional $\mathrm{KrF}$ resist as shown in Fig.4. It has been suggested that the adamantane structure of ADTB is useful to improve the etch resistance of the resist. 


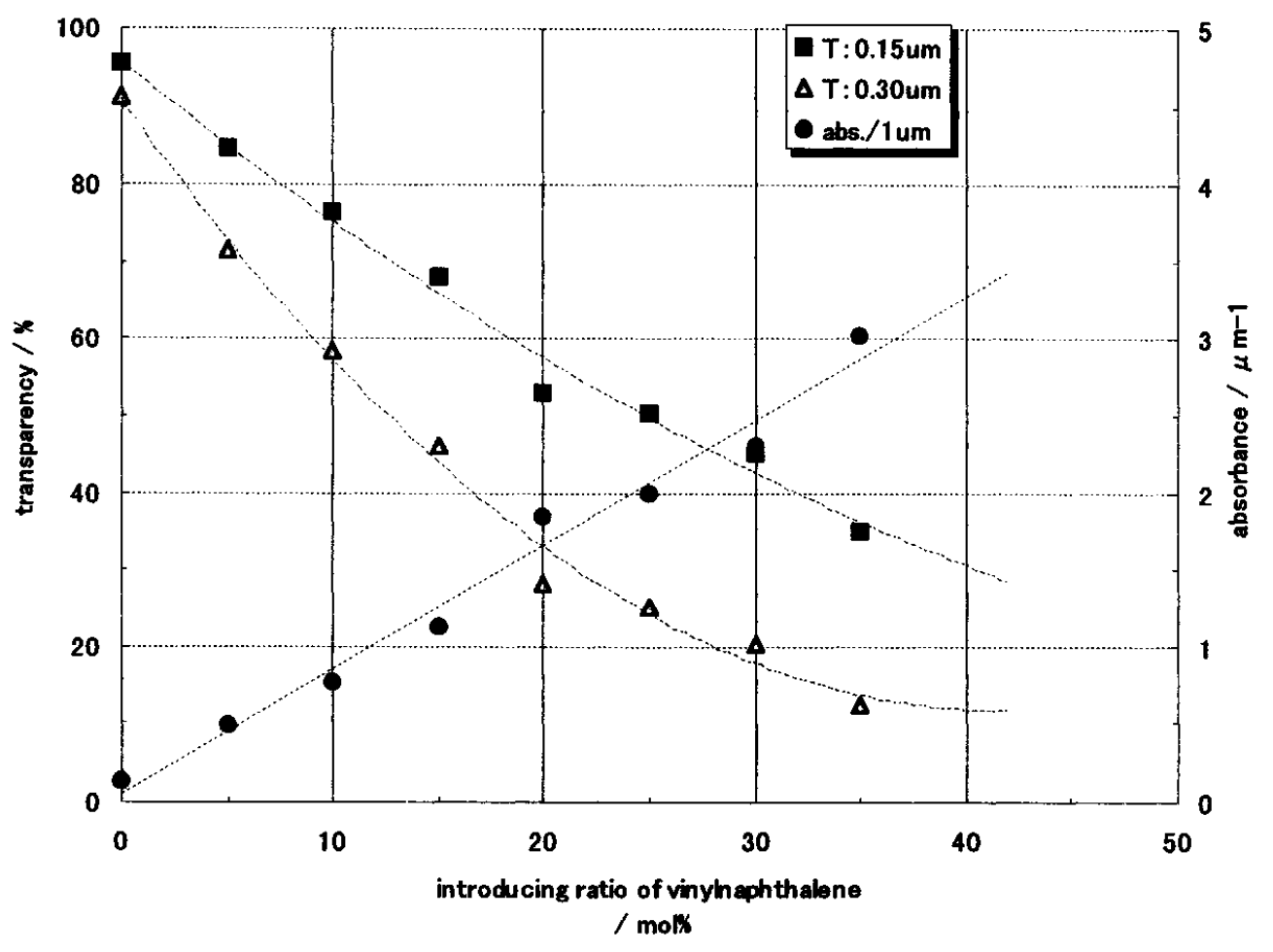

Fig.3 Dependence of absorbance and transparency on introducing ratio of vinylnaphthalene at $193 \mathrm{~nm}$. ; absorbance of $1 \mu \mathrm{m}$-thick film, $\mathbf{E}$; transparency of $0.15 \mu \mathrm{m}$-thick film, $\Delta$; transparency of $0.30 \mu \mathrm{m}$-thick film

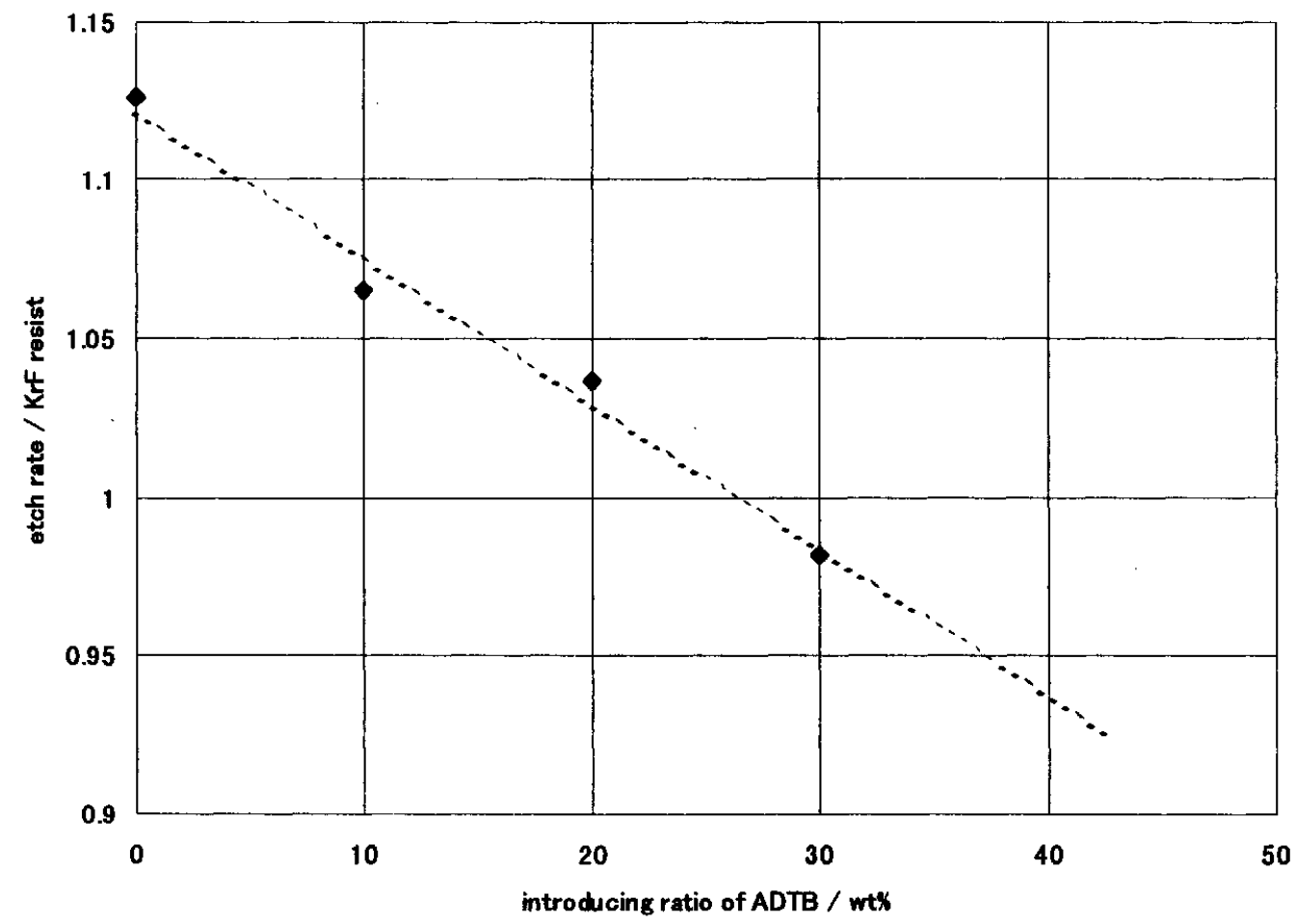

Fig.4 Dependence of etch rate on introducing ratio of ADTB. VN25 was used as a base polymer. Etch rate was normalized by a conventional $\mathrm{KrF}$ resist. 
ADTB has two t-butyl esters as shown in Fig.2. A t-butyl ester copolymer generally requires a high PEB temperature (above ca. $140^{\circ} \mathrm{C}$ ) to drive the deprotection efficiently ${ }^{4)}$. On the other hand, a tetrahydropyranyl ester copolymer requires a low PEB temperature (ca. $100{ }^{\circ} \mathrm{C}$ ). VN25 has tetrahydropyranyl ester as a protecting group, and so the exposed films were baked at $110^{\circ} \mathrm{C}$.

If $\mathrm{ADTB}$ has the same stability as t-butyl ester copolymer at this $\mathrm{PEB}$ temperature, ADTB will not work efficiently in the VN25/ADTB resist. Fortunately, the working temperature of ADTB is $110^{\circ} \mathrm{C}$, which is the same as the deprotection temperature of tetrahydropyranyl ester in VN25.

The VN25/ADTB-30 (introducing ratio of ADTB; $30 \mathrm{wt} \%$ ) was exposed to ArF excimer laser and processed, baked at $110^{\circ} \mathrm{C}$ for 60 seconds, and then developed in $0.238 \%$ TMAH aqueous. 0.13 $\mu \mathrm{m}$ lines/spaces pattern was successfully fabricated at an exposure dose of $20.8 \mathrm{~mJ} / \mathrm{cm}^{2}$. A scanning electron microscope image of the fabricated pattern is shown in Fig.5.

We suppose that t-butyl ester-copolymer and ADTB have different deprotection mechanisms.

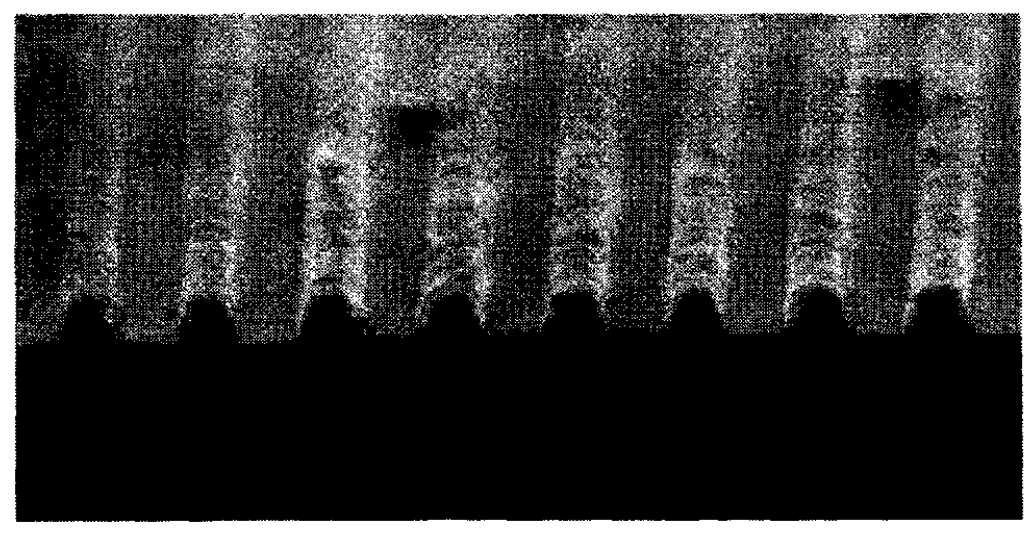

Fig. 5 SEM image of $0.13 \mu \mathrm{m}$ L/S in a $0.17 \mu \mathrm{m}$-thick film of VN25/ADTB=7:3 resist on a bare Si wafer obtained from ArF stepper $\left(\mathrm{NA}=0.55, \sigma=0.8\right.$ ) at $20.8 \mathrm{~mJ} / \mathrm{cm}^{2}$ dose. (S/B; $120^{\circ} \mathrm{C}-90 \mathrm{sec}$, PEB; $110^{\circ} \mathrm{C}-60 \mathrm{sec}$, Development; $0.238 \mathrm{wt} \%$ TMAH solution $40 \mathrm{sec}$.)

\section{Conclusion}

A thin film of resist containing naphthalene is suitable for ArF excimer laser lithography. Thin films are advantageous in terms of transparency. Naphthalene structure has good dry etch resistance and, moreover, ADTB improves it. The VN25/ADTB-30 resist was exposed to ArF excimer laser and $0.13 \mu \mathrm{m}$ lines/spaces pattern was successfully fabricated at an exposure dose of $\mathbf{2 0 . 8}$ $\mathrm{mJ} / \mathrm{cm}^{2}$.

\section{References}

1. T. Naito, K. Asakawa, N. Shida, T. Ushirogouchi and M. Nakase: Jpn. J. Appl. Phys. 33 (1994) 7028.

2. N. Shida, T. Ushirogouchi, K. Asakawa and M. Nakase: J. Photopolym. Sci. Technol. 9 (1996) 457. 3. T. Ushirogouchi, K. Asakawa, T. Okino, N. Shida, N. Kihara and M. Nakase: Jpn. J. Appl. Phys. 36 (1997) 7625.

4. R. D. Allen, J. Opitz, C. E. Larson, T. I. Wallow, R. A. DiPietro, G. Breyta, R. Sooriyakumaran and D. C. Hofer: J. Photopolym. Sci. Technol. 10 (1997) 503. 